\title{
Occupational Therapy Intervention for Hemiplegic Shoulder Pain in Adults Post-Stroke: A Zimbabwean Perspective
}

\author{
*Lee-Ann Juliana Jacobs-Nzuzi Khuabi. B Sc. OT (UCT), MPH (UCT), PhD OT (SU). \\ http://orcid.org/0000-0003-0684-5373 \\ Senior Lecturer, Division of Occupational Therapy, Dept of Health and Rehabilitation Sciences, Stellenbosch University, South Africa.
}

\author{
Susan de Klerk. B OT (SU), DHT (UP), M OT (SU). http://orcid.org/0000-000 I-7639-93 I 9 \\ Senior Lecturer, Division of Occupational Therapy, Dept of Health and Rehabilitation Sciences, Stellenbosch University, South Africa.
}

\section{Mary Tapfuma. B Sc. OT (UZ), M OT(SU). https://orcid.org/0000-0003-37 I 7-7902}

Senior Occupational therapist, Keetmanshoop Hospital, Ministry of Health and Social Services, Namibia.

Background: Stroke is a leading cause of disability in Zimbabwe. Hemiplegic shoulder pain (HSP), a secondary complication of stroke, impedes the functional recovery of the upper limb and occupational engagement. Occupational therapy intervention, comprising assessment and treatment, seeks to promote health and well-being through facilitating improvement in occupational engagement. There is a lack of documented evidence on occupational therapy intervention practices (i.e., assessment and treatment) of HSP in the context of Harare, Zimbabwe. To allow for an increased understanding of HSP management, this study explored occupational therapists' assessment and treatment practices of post-stroke HSP in Harare, Zimbabwe.

Method: This explorative study included six experienced occupational therapists from three public hospitals in Harare, Zimbabwe. Data were collected through semi-structured interviews and analysed using qualitative content analysis.

Results: Data analysis revealed three themes, i.e., assessment of post-stroke HSP is all encompassing; key components of post-stroke HSP treatment practice and challenges in occupational therapy practice of post-stroke HSP in Harare.

Conclusion: Occupational therapy intervention practice for post-stroke HSP in Harare includes an eclectic approach, with preventative practices as a key component of treatment. Intervention should strive to be occupation-based and holistic encompassing considerations of environmental factors and the indicators of HSP.

Keywords: public health care, occupational therapy intervention, clinical practice, neurological upper limb conditions

\section{BACKGROUND AND LITERATURE REVIEW}

Globally stroke is a leading cause of death and disability-adjusted life years ${ }^{1,2}$. Feigin et al. highlighted that the incidence of stroke in low to middle-income countries more than doubled considering data from 56 population-based studies between 1970 and 2008 in their systematic review, which also highlighted a $42 \%$ decrease in stroke incidence in high-income countries ${ }^{3}$. Stroke is one of the leading non-communicable diseases causing premature death and disability in Zimbabwe ${ }^{4}$. Matenga ${ }^{2}$ estimated the stroke incidence rate in the capital city Harare to be at a standardised rate of 68 per 100000 . This number may be far higher than the prevailing rate due to the rise of non-communicable diseases' prevalence rates and neurological complications which follow HIV infection ${ }^{4,5}$.

Secondary complications of a stroke, such as hemiplegic shoulder pain (HSP), interfere significantly with the return of limb voluntary movement and control, and the engagement of the affected extremities in daily occupations ${ }^{6}$. Gilmore et al. reported that diagnosing HSP is complex and should be done clinically based on signs and symptoms. Pain and loss of range of motion are key indicators ${ }^{7}$. The main causes and presentation of HSP have shown to be multifactorial and can include shoulder subluxation, shoulder-hand syndrome, abnormalities in muscle tone, rotator cuff injuries, frozen shoulder, altered sensation, central post-stroke pain and pre-existing pathological conditions including but not limited to, arthritis ${ }^{7}$. The presence of post-stroke HSP can restrict the individual's execution of activities such as eating, grooming, dressing, transfers and rolling in bed. In addition, it can disturb sleep which negatively impacts quality of life ${ }^{8}$. Post-stroke HSP has been associated with poor rehabilitation outcomes, prolonged hospital stay and delayed functional recovery?.

Occupational therapy intervention for stroke survivors improves participation in roles, tasks and daily activities that are meaningful to the individual ${ }^{10}$. A core assumption in occupational therapy is the belief that the participation of individuals in desired meaningful daily activities promotes health and well-being " . As post-stroke HSP has the potential to limit the individuals' participation and engagement in functional and enabling activities, intervention aims to restore and remediate occupational performance deficits through appropriate positioning, facilitating movement through therapeutic activities and increasing passive range of movement and the use of external support ${ }^{7}$. The occupational therapist's interventions comprise both assessment and treatment practices. Initially the occupational therapist assesses the impact of the HSP on the individual's occupa- 
Table I: Participant demographic profile.

\begin{tabular}{|c|c|c|c|c|c|c|}
\hline Participant & PI & $\mathrm{P} 2$ & P3 & P4 & P5 & P6 \\
\hline Gender & $F$ & $M$ & M & M & $\mathrm{F}$ & $M$ \\
\hline Age & 30 & 32 & 29 & 31 & 25 & 30 \\
\hline Designation & Senior OT & Senior OT & Senior OT & Senior OT & Senior OT & Senior OT \\
\hline $\begin{array}{l}\text { Highest } \\
\text { qualification }\end{array}$ & B.Sc. (Hons) OT & Masters of OT & B.Sc. (Hons) OT & B.Sc. (Hons) OT & B.Sc. (Hons) OT & B.Sc. (Hons) OT \\
\hline $\begin{array}{l}\text { Number of } \\
\text { years in service }\end{array}$ & 5 & 6 & 2 & 5 & 2 & 5 \\
\hline $\begin{array}{l}\text { Number of } \\
\text { years in stroke } \\
\text { rehabilitation }\end{array}$ & 3 & 2 & 2 & 4 & 2 & 2 \\
\hline
\end{tabular}

tional performance and engagement ${ }^{10}$. A client-centred, goal-driven occupational therapy treatment programme is then formulated to facilitate improvement in limitations in occupational performance and engagement ${ }^{10}$. Existing guidelines are from high-income contexts and may not apply as a result of constraints in resources and infrastructure in low to middle-income countries ${ }^{12,13}$. The occupational therapy assessment and treatment practices offered to adult post-stroke survivors with HSP in Zimbabwe is unknown. We found no documented evidence on intervention practices which highlight how occupational therapists are, or should be, addressing post-stroke HSP in the context of Harare. Anecdotal evidence from the public service context of Zimbabwe assumes that persons with post stroke HSP is not appropriately assessed in terms of the cause and the effect on occupational performance. When clients do present with pain, it is accepted to be part of the treatment process and not necessarily considered a potential symptom of HSP. Undertaking research in this field could highlight current practice towards a better understanding and improved rehabilitation outcomes by potentially reflecting current needs for further education and training in the Zimbabwean context.

\section{Research question}

What are the current intervention practices (i.e. assessment and treatment) used by occupational therapists working in Harare public hospitals in the management of clients with post-stroke HSP?

\section{METHOD}

\section{Research design}

The research was performed by means of a qualitative exploratory study within an interpretivist paradigm as this design allows researchers to make sense of human experience, towards exploring and understanding the personal meaning that participants attribute to the research phenomenon ${ }^{14}$. Semi-structured interviews were conducted with those participants who consented.

\section{Participants}

Harare province has three major public health facilities where occupational therapy services are offered. These are Harare and Chitungwiza central hospitals and Parirenyatwa group hospital. Participants were recruited from all three health institutions. The study population $(N=16)$ included occupational therapists registered with the Health Professions Council of Zimbabwe, who had two or more years of experience in stroke rehabilitation and worked at one of the three central hospitals in Harare province.
Purposive sampling was used, with snowballing as a recruitment strategy ${ }^{14}$. After permission was granted by the participating health institutions administration, potential participants were recruited through discussions held with the heads of departments. Those who consented to participate helped identify additional participants. The final sample included six participants. Descriptive information regarding participants can be seen in Table I (above).

\section{Data collection}

The third author completed data collection after written informed consent was obtained. Semi-structured interviews, with the use of an interview guide, were conducted with all six participants. The interview guide was developed based on current literature and aligned with the objectives of the study. Each interview was audio-recorded and took place at the participants' workplace. Rigour and trustworthiness were upheld by strategies of credibility and confirmability, achieved through member checking following data analysis, whereby provisional categories and themes were sent to participants to verify. Structural coherence was upheld by reflecting on the research objectives throughout the process, reflexivity through reflective journaling and peer debriefing through consultation with qualitative researchers. Transferability and dependability were strengthened by thick descriptions and verbatim transcriptions ${ }^{15}$.

\section{Data analysis}

Qualitative content analyses were done deductively as it allowed the use of concepts, identified from existing theory on post-stroke HSP management, as initial categories for coding ${ }^{16}$. With this approach, existing theory is used as a foundation for coding, but it allows for new categories to emerge from the data. The following steps were taken to categorise the data:

I. Verbatim transcription of the audio-recorded data. To reduce transcription errors, recordings were replayed once after transcription and compared with the transcripts.

2. Initial categories were selected from literature that described occupational therapy assessment and treatment practices for patients with post-stroke HSP.

3. Each transcript was read line by line, and phrases that either described assessment or treatment practices were highlighted.

4. Highlighted phrases were then coded into pre-determined categories. New categories were formulated for text that did not fall into pre-determined categories.

5. Subcategories were identified by further identifying the details provided within each highlighted phrase. 


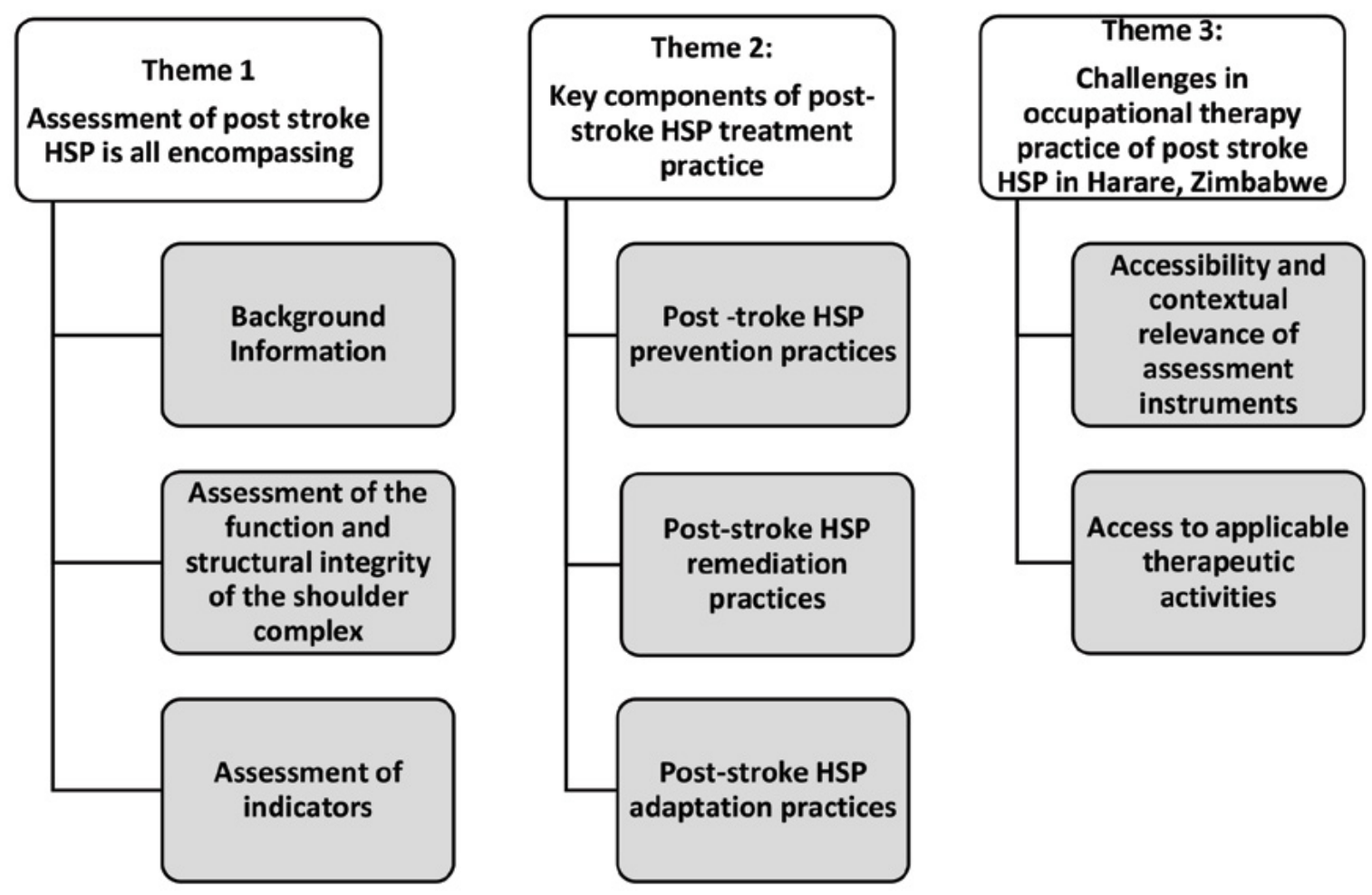

Figure I: Themes and Categories.

\section{Ethical considerations}

Permission to carry out the study was sought and obtained from the following prior to sampling and data collection: The Health Research Ethics Committee (HREC) of Stellenbosch University (Ethics reference number: SI4/06/I3I); The Ministry of Health and Child Care Zimbabwe Permanent Secretary; Harare Central hospital ethics committee (Reference number: HCHEC27 I0I4/73); Parirenyatwa and Chitungwiza central hospitals' clinical directors; and The Medical Research Council of Zimbabwe (Reference: $M R C Z / B / 770)$. Written consent to participate was obtained from interested participants. Interview dates and venues were negotiated with each participant. Confidentiality was upheld by using pseudonyms and a password-protected computer.

\section{FINDINGS}

From the data analysis, three themes emerged, namely: Assessment of post-stroke HSP is all-encompassing; Key components of post stroke HSP treatment practice and Current challenges facing occupational therapy practice of post stroke HSP in Harare, Zimbabwe. (see Figure I above).

\section{Theme I: Assessment of post-stroke HSP is all encom- passing}

This theme is subdivided into three categories and reflects occupational therapy assessment of clients with post-stroke HSP. This included a comprehensive history taking, a physical examination of the structure and functioning of the shoulder complex and obtaining information on the client's daily lived experience of post stroke HSP. Participants refer to the use of an "eclectic approach to assessment", which encompasses the use of multiple sources and methods of assessment as is reflected by P3:

"As occupational therapists we try to use what we call the eclectic approach where we mix quite a lot of assessments. We take a lot of information from different sources" [P3]

\section{Category I: Background information}

Participants highlighted that the assessment of post-stroke HSP commenced with a comprehensive client medical, occupational, and social history. Gathering information on a client's life roles and interests, allowed for client centred treatment planning.

"There is need for a comprehensive history for one to come up with a well- informed assessment of the patient."

"... even we have to use the role check list and the interest checklist in trying to understand the client better... So, you generally use the eclectic approach but first of all you take the history of the client then you write the presenting complaints and so forth " $[\mathrm{P3}]$ "We want to know what the patient was doing before the present condition. Was he a manager, was he a gardener, etc.?" [P4]

"I would do a holistic assessment of this patient...l assess what kind of activities they are interested in... so that I can incorporate all those activities in my treatment" [P5]

\section{Category 2: Assessment of the structural integrity and functional state of the shoulder complex}

Participants shared the importance of assessing the functional and structural integrity of the shoulder complex as changes in body function and structure caused by the stroke could result in HSP. This assessment has to consider both biomechanical and neurological aspects as structural changes in the shoulder could be due to pre-morbid orthopaedic conditions, unrelated to the stroke. Findings reflect the formal and informal assessment of the performance components affected in person with HSP and included: an assessment of muscle tone; range of motion; muscle strength; shoulder pain (i.e., location, intensity, and quality); observation of 
the client's posture in a seated or standing position; examination for subluxation; examination of the upper limb for oedema and the assessment of sensation. Participants explicated that pain was assessed with visual analogue pain scales and x-rays were used to inform their assessment of severe cases of HSP.

"There are so many factors that cause pain, and you want to look at all of them. Is it a muscle tear? Is it arthritis?" [P2]

"I would want to know the aggravating factors and under what circumstances does the pain disappear. I use the visual analogue scale and it depends on the level of education of the patient. I then assess subluxation, oedema, muscle tone, voluntary movement and activities of daily living." [P4]

"We are looking at whether there is a dislocation or not, that's a subluxation, that's the key factor which we look at on an $x$-ray especially for the shoulder joint." [P6]

\section{Category 3: Assessment of the impact on occupational performance}

Findings show that the impact of post-stroke HSP on occupational performance should be noted. This was deemed important, as the impact of post-stroke HSP on occupational performance is the primary concern of the client and a core focus of occupational therapy as a profession. Participants mentioned the need for the assessment to highlight the impact of psycho-social aspects on occupational performance.

“... everything bottles down to activities of daily living. Whatever we do, ultimately has to result in some form of occupation. Particularly looking at all the relevant activities of daily living depending on the level of function of the patient" [P2].

".. it is mostly about ADLs...how is it (HSP) affecting their work, schooling, their hobbies or family roles. Of course, you wouldn't forget their cognitive and perceptual aspects..." [PI]

"They won't even tell you about sensation but about what they can't do" [P3]

\begin{abstract}
"Generally, I would do a holistic assessment of my patient. Considering the psychosocial factors as they contribute to my patient's progress. If there is any stress associated with their motivation.... I assess what kind of activities they are interested in... so that I can incorporate all those activities in my treatment." [P5]
\end{abstract}

\section{Theme 2: Key components of post stroke HSP treat- ment practice}

This theme reflects participants' views on the key components that should comprise treatment practices of post-stroke HSP, i.e. prevention, remediation, and occupational adaptation practices. The current study found that all participants mentioned that they applied a combination of the above three practices in treating clients with post stroke HSP. Prevention practices included: education of both the client and caregiver; use of assistive devices for external support, positioning/stabilisation, and daily exercise. Remediation practices included: the use of physical agents such as heat and ice; transcutaneous electrical nerve stimulation (TENS) and therapeutic activities. Hands-on techniques such as scapula mobilisation, range of motion exercises and massage were also mentioned as part of the remediation practices. Specific remediation approaches to practice mentioned by the participants were Rood, Bobath and Brunnstrom ${ }^{17}$. The selection of treatment practices was influenced by the participants' professional education and the availability of treatment equipment at their workplaces. Participants highlighted that they applied knowledge from literature. Adaptation practices included: bilateral hand activities during grooming; dressing without triggering pain; energy conservation during activities of daily living and one-handed techniques.

"Treatment of this patient is multi-faceted." [P2]

\section{Category I: Post stroke HSP prevention practices}

Participants reported that prevention was the preferred treatment practice for clients post stroke HSP.

Education of clients and their caregivers (both formal and informal), coupled with the correct therapeutic handling skills were stated as an important risk-reducing component of post stroke HSP. Clients and caregivers were taught to "respect pain by working within a pain-free shoulder range" of movement. Caregivers were strongly discouraged from pulling the affected arm. Client and caregiver education included knowledge and skills pertaining to proper sleep and seating positions; correct transfer and grooming techniques; the use of assistive devices and daily exercise. Amongst the assistive devices mentioned for positioning, slings were commonly prescribed specifically where clients presented with a subluxed shoulder joint. Other positioning devices included pillows, lap-trays for wheelchair users, figure-of- 8 bandaging and shoulder cuffs.

"Actually, I have realised that the caregivers are the major reason for shoulder pain in clinical stroke patients... We always make sure we work within the pain limit of the (glenohumeral) joint because we don't want to injure the joint. We also teach the patient and the caregiver's joint protection techniques so that they don't aggravate the problem." [P4]

"So whatever activity that you are going to use to work on their range of motion and at the same time taking consideration of their pain" [PI]

"I think early intervention and proper education to the client (especially from an occupational therapist) can - prevent shoulder pain..." [P6]

“We position our patients' well, when sleeping, seating, using slings during transfers, pillows when seating or sleeping. When using a wheelchair, you can use the lap board so that they can rest their arm on the elbow joint" [P2]

\section{Category 2: Post-stroke HSP remediation practices}

Assessment results inform remediation practices. Treatment practices were targeted either directly to reduce pain or to remediate neurological impairments of HSP post stroke through the application of various neuro physiological approaches. Heat, ice and transcutaneous electrical nerve stimulation (TENS) were the common physical agents used in preparation for activity participation. Clients were taught to do passive range of motion exercises. Activities towards addressing performance components, including skateboards, sanding, shoulder wheels, stacking cones and solitaire, were the most used and reflects a bottom-up approach. There were mixed reporting regarding the use of overhead pulleys. Some 
participants mentioned the use of prior occupations as a treatment method (a top-down approach).

\begin{abstract}
"Most of them they have high tone or low tone, we need to normalise the tone through weight bearing, icing, brushing, massage and the likes for tone normalisation then after that we need to engage the patient in active range of motion exercises because we usually do cone stacking, solitaire, where the affected limb is not functional we usually use bilateral movements with those patients, then we also there is also need for us where there is pain we also need to use hot packs on the shoulder to manage the pain first after managing the tone we manage the pain through hot packs as an occupational therapist. When the pain persists we usually refer to the doctor for medication so that we can accomplish our activity without pain." [P6]
\end{abstract}

"...so there are different approaches e.g. the Rood sensory technique, Brunnstrom technique, the Bobath approach... Just depending on what you are prioritising or what you are working on first or you can use them together" [PI]

"With resources available I prefer using TENS. We don't have it but some guys bring it and we use it and it's helpful..." [P2]

“We use pulleys, skateboards, the shoulder wheel” [P4]

"We try to incorporate the patient's normal activities prior to the injury (HSP) so that the treatment method can be meaningful to the patient..." [P4]

\section{Category 3: Post stroke HSP adaptation practices}

Participants reported that in cases of severe post stroke HSP, there were specific adaptive or compensatory practices they taught clients and caregivers to use so as to improve occupational performance; including energy conservation, bilateral upper limb activities, onehanded techniques and joint protection techniques to execute daily activities efficiently.

"... sometimes we give them slings for positioning and also to support the subluxed shoulder and this also allows the shoulder to be in a normal neutral position... [PI]

There is the shoulder cuff... it helps fixate the shoulder usually during task performance because usually pain comes when there is movement of the shoulder". [P6]

"For instance, grooming, we advise the patients to do hand over hand. So which ever activities of daily living that are relevant to the patient we would advise to have them done" [P2]

"We teach them how to don and doff let's say a shirt or a pair of trousers with less pain... if the patient complains of great pain, then we teach them one-handed techniques and other compensatory movements for them to be independent in ADLs..." [PI]

Theme 3: Challenges in occupational therapy practice of post stroke HSP in Harare, Zimbabwe

This theme reflects the challenges facing occupational therapists when providing intervention for clients with post stroke HSP. The challenges include limited access to and the contextual irrelevancy of assessments and limitation in the implementation of occupation- based approaches during the management of post stroke HSP.

Category I: Limited accessibility and applicability of assessment instruments

Participants reported that within public hospital settings the choice of assessment methods and sources are restricted due to lack of available assessment instruments. As a result, therapists rely more on readily accessible and affordable assessment methods such as observation. Assessment instruments supported by literature were in some cases perceived to lack cross cultural validity which impacts utility.

"We use observations because it is quite administrative in nature because at such public hospitals you may want to have standard assessment tools but to have them photocopied or what, it is quite a challenge. So those are some of the challenges and you end up doing what is most convenient" [P3]

“... but unfortunately, we don't have a goniometer, so we just estimate .... We also assess sensation whenever necessary because some of our patients might have paraesthesia ... We don't have a standardised tool for assessing sensation ... because of limited resources we use our hands" [P2]

"We don't have it for now. We used to have it and now we don't have the full tool but an adapted tool. The tool was devised in one of the western countries, so we now need to adapt it to suit our situation and (to be) applicable to our patients" [P4]

"I use an adapted Barthel Index scale because we don't have the real one... [P5]

We just use the visual analogue scale. Even though Zimbabwe is a literate nation, some of the elderly might still not be able to give you a reliable response, so we break it down to the local languages" [PI]

\section{Category 2: Limited access to applicable therapeutic activities within the practice setting}

Participants reported financial constraints contributing to the limited use of activities during occupational therapy treatment, resulting in the application of hands-on therapy approaches only (refer to Theme 2 above), instead of also engaging in activities as part of treatment. Participants reported the lack of financial resources hindering the procurement of requirements for occupation-based treatment, within the client's interest and frame of reference.

"In our department we have limited equipment..." [P5].

“... like we don't have much of the equipment for use for proper care for the patient, so we end up using hands-on modalities which do not require any other external equipment. So, in selecting our activities we usually look at what's available, then we look at the client's age then the severity of the CVA, gender and the likes. [P6]

But the challenge is that we don't have proper tools for the workshop except for the work bench and the materials." [P3]

\section{DISCUSSION}

The current study sought to explore the current occupational therapy assessment and treatment practices for post-stroke HSP in the Zimbabwean context. The findings were similar to those from 
a review of the evidence for management of shoulder pain poststoke i.e. an eclectic approach to assessment and treatment ${ }^{18}$. A key finding from the current study is that post-stroke HSP management necessitates comprehensive and holistic assessment. Participants believed the starting point of the assessment should include collecting information on the client, their occupations and the environment in which this occurs (top-down approach to assessment). Similarly, Mattingly ${ }^{19}$ highlights that occupational therapists need to collect information on a client's occupational goals as a means to understand occupational performance limitations, thereby facilitating treatment that is relevant and responsive.

The present study found that therapists assessed the functional and structural integrity of the shoulder complex. The physical examination of the structural integrity and the functional state of the shoulder complex is important in establishing the cause of post stroke $\mathrm{HSP}^{18}$. In addition, authors have stated that the shoulder complex, the neck and the elbow should also be assessed, given that pain can be transferred to the shoulder from diseases in these areas ${ }^{20}$. The present study did not explore whether therapists assessed the scapula position, scapula alignment and scapula-humeral rhythm as part of routine assessment of post-stroke HSP. However, research shows that scapular alignment plays an important role in the functional use of the upper limb ${ }^{21}$. Optimal scapulohumeral rhythm has been shown to be important as a pre-requisite for reach and its role in preventing subacromial impingement which may cause shoulder pain ${ }^{21}$.

The findings from the present study support the notion of Byrne and Ridgeway ${ }^{22}$ that the orthopaedic and the neurological systems are interrelated and therefore, both systems should be considered during assessment of a painful shoulder. Participants in this study explicated that their physical assessment included: shoulder pain intensity/severity, sensation, muscle tone, muscle strength, range of motion, posture, and oedema. They however did not report on the assessment of the trunk which is understood to be important in the evaluation of the upper limb in post stroke HSP'. Participants stated that their assessment of pain included the use of a visual analogue scale. Harrison and Field ${ }^{23}$ however, caution that whilst there are various pain scales, such as visual analogue scales, none are suitable for the assessment of post- stroke pain. Furthermore, given the range of impairments that stroke patients may present with, therapists need to ensure that the choice of pain scale matches the client's abilities as some impairments of stroke may impact on the client's ability to report pain (such as cognitive or perceptual impairments) ${ }^{24}$. Participants reported having assessed the impact of shoulder pain on the client's daily occupational performance in addition to pain and range of motion ${ }^{7}$. This focus is in agreement with those authors who recommend that the assessment of shoulder pain should include the impact thereof on occupational performance ${ }^{25,26}$. Study participants used the Barthel index to assess limitations experienced in executing self-care activities, which is in line with current practice trends ${ }^{25,26}$.

Study findings revealed that psycho-social factors including client's motivation and stress were considered during assessment. Assessment of psycho-social factors in persons with post- stroke HSP provides a benchmark for progress or deterioration in pain management. Some authors propose that it is essential to address both the underlying cause of pain and the associated psycho-social factors that could impact effective pain management ${ }^{27,28}$. Gilmore supports the psychological management in persons with post stroke HSP7. Instruments used to assess psychological aspects include The Beck Depression Inventory ${ }^{29}$, The Geriatric Depression Scale ${ }^{30}$ and The Hospital Anxiety and Depression Scale ${ }^{31}$. None of these instruments have, however been validated for use in the Zimbabwean context.
As occupational engagement occurs within the preferred and usual context (environment) of persons with post stroke HSP, it should be noted that the environment either supports or limits occupational performance and therefore should be an important consideration of occupational therapy interventions ${ }^{32}$. The importance of the assessment of the environment is further supported by ecological theories of movement that have emphasised the influence of the environment on the motor performance of individuals with hemiplegia ${ }^{27}$. However, within the present study, participants did not report to routinely assess environmental factors.

The findings of the study revealed a general limitation in the availability and use of formal assessments. Assessments further were not always contextually relevant and lacked evidence of cross-cultural validity. This finding is common in developing contexts and calls for research that aims to validate assessments for contexts other than those where the assessment were developed ${ }^{33}$.

Participants from the current study considered prevention as the best intervention method for post stroke HSP, this is supported by Dyer et al. $^{34}$ and Gilmore et $\mathrm{al}^{7}$. Consistent with the results of other studies, patient and carer education with regards to correct positioning, correct handling skills and maintaining passive range of movement was pivotal in the management of post stroke HSP. Proper positioning assists with maintaining optimal joint alignment ${ }^{6}$. Passive range of motion exercises have been proven to play a role in preventing contractures, maintain pain-free joint motion and to prevent secondary complications associated with pain ${ }^{18}$. Study participants employed several handling techniques during therapy and patients and caregivers were instructed on how to apply these at home. In line with literature, the following handling techniques were found to be in used: avoiding traction or forceful movements, avoiding pulling the hemiplegic arm, always supporting the arm during movement, working within a pain free range, avoiding shoulder movements of more than 90 degrees active/passive flexion and abduction during therapy, and ensuring that there was external rotation during passive movement ${ }^{18,35}$.

Participants employed several types of remediation methods which included physical agents, external supports, mobilisation, enabling activities and referral. The use of physical agents including electrical stimulation, especially in preparation for purposeful activity is supported in literature ${ }^{18,36,37}$. The commonly used physical agents were ice and heat. Heat was applied in the form of hot packs ${ }^{38}$. Evidence is available to support the use of heat to decrease pain, joint stiffness, and increase the extensibility of soft tissue ${ }^{38}$. Ice packs can be used to relieve pain, oedema, and spasticity all of which are associated with post stroke $\mathrm{HSP}^{38}$. Only one of the three participants using TENS was formally trained in its use, which contradicts some practice guidelines which state that there must be some form of documented evidence to show if the therapist possesses knowledge and skills to administer such physical agents ${ }^{38}$.

In contrast to the evidence on treatment practices for post stroke HSP, there was no evidence in the findings of this study on the use of Functional Electrical Stimulation (FES) $)^{18,39,40}$, vibration ${ }^{36}$, point stimulation $^{36}$, Carr and Shepherd's positional stretching program ${ }^{41}$ or strapping ${ }^{40,42}$. Slings were the common external supports which were prescribed by therapists, although there is little research evidence which support their effectiveness ${ }^{18,42}$. The types of mobilisation which were found to be in use were scapula mobilization and passive/ active range of motion exercises. Literature supports the use of scapular mobilisation to improve the scapulohumeral rhythm which is a prerequisite for good arm function ${ }^{7,18,35}$.

Participants reported use of the following commonly utilised 
treatment techniques namely Roodt, Brunnstrom and Bobath. They however did not report on Task-oriented training approaches (TOT) that include: Constraint Induced Movement Therapy (CIMT), the Occupational therapy task oriented approach or augmented TOT approaches such as mirror therapy, action observation, mental practice, virtual reality and robotics ${ }^{43}$. The benefit and effectiveness of these approaches is an ongoing debate in literature and research on this topic and beyond the scope of this article. A recent study however suggests some evidence that the use of CIMT may be superior in improving hand function in persons following stroke. This has to be viewed with caution as the sample included only 30 patients, all with a high functioning affected side ${ }^{44}$.

In the current study, the challenges in occupational therapy practice for persons with post-stroke HSP was identified to be a lack of applicable and accessible assessment instruments as well as suitable therapeutic activities. An essential requirement for effective occupational therapy intervention is a comprehensive assessment. Assessment instruments, however, have to be accessible and available in the practice context. Furthermore, therapists must be familiar with their use and the measures must be contextually relevant. Authors from South Africa highlighted similar challenges to assessment (in an attempt to introduce contextually relevant occupation based approaches) as those reported by their Zimbabwean colleagues ${ }^{45}$.

Participants further reported the use of activities towards improving performance components which can promote movement, alter mood and divert the mind from the pain ${ }^{36,40}$. These findings reflect that a bottom-up approach which concentrates on the remediation of individual performance components was preferred to the top- down approach, which focuses on the level of occupational performance of the stroke survivor. Authors have criticised using a bottom-up approach as it lacks value and meaning to the patient's occupational life ${ }^{6,12}$. In contrast, the top-down approach is thought to be more client-centred as it is more likely to address what is relevant and important to the client, particularly when occupational participation occurs in context ${ }^{6}$. Occupational therapists in Zimbabwe should consider following a top-down or mixed approach (i.e., both bottom-up and top-down) instead of the sole use of a bottom-up approach. The International Classification of functioning, disability and Health (ICF $)^{46}$ is an example of a framework that allows therapy intervention to include a mixed approach. Given current demands on the Zimbabwean health system, service provision within group settings could increase service delivery coverage. Group interventions such as the functional group model, an occupation-based version of group intervention, may be a suitable consideration ${ }^{47}$. The use of occupation-based practice within the clients' context may further seek to address the challenge of financial constraints that hinders the acquisition of appropriate therapeutic activities within the practice setting.

\section{CONCLUSION}

Findings reflect that occupational therapy assessment and treatment practice for post-stroke HSP in Harare, Zimbabwe includes the use of an eclectic approach allowing occupational therapists to look beyond the shoulder complex in assessing the impact of HSP on a client's occupational performance. Additional key components of post stroke HSP assessment should include considerations of client's occupational goals, environmental factors, the indicators for post stroke HSP and the use of relevant assessment instruments. Keeping true to occupational therapy's focus on occupation, the treatment of post stroke HSP should strive to include occupationbased approaches. Post stroke HSP prevention practices are a key component of treatment. High demands on public health services, coupled with other contextual factors, necessitate that occupational therapists in Harare seek more cost-effective evidenced-based modes of service delivery such as functional groups or the provision of interventions within clients' contexts.

\section{LIMITATIONS OF THE STUDY}

The study findings did not highlight the clinical reasoning that underpins choice of assessment and treatment approaches for post stroke HSP. The study's small sample and location within Harare does not make these findings generalizable. However, the purpose of the study was to provide a deeper understanding of the phenomenon rather than to generalise the results.

Future Research could seek to explore this topic in other provinces in Zimbabwe which could allow for increased transferability of the findings which could then be used in combination with evidencebased practice to develop national guidelines for the management of post-stroke HSP in Zimbabwe. Further research could be conducted to explore the lived experience or the coping strategies of adults with post-stroke HSP. This may help elucidate the environmental factors that impact on the recovery path of clients.

\section{ACKNOWLEDGEMENTS}

We would like to thank the Harare public health facilities and the study participants for their willingness to participate in this research.

\section{CONFLICTS OF INTERESTS}

The authors declare no competing interests.

\section{AUTHOR CONTRIBUTIONS}

Lee-Ann Jacobs-Nzuzi Khuabi and Susan de Klerk supervised the data collection and analysis and contributed to the writing, editing and submission of the article. Mary Tapfuma conceptualized the project and completed the data collection, data analysis and contributed to the write up of the article.

\section{REFERENCES}

I. L Murray CJ, Vos T, Lozano R, Naghavi M, Flaxman AD, Michaud C, et al. Disability-adjusted life years (DALYs) for 29l diseases and injuries in: a systematic analysis for the Global Burden of Disease Study 2010. Lancet [Internet]. [cited 202I Apr 28];380:2197-223. Available from: www.thelancet.com

2. Lozano R, Naghavi M, Lim SS, Ahn MPH SY, Alvarado MB, Andrews MPH KG, et al. Global and regional mortality from 235 causes of death for 20 age groups in 1990 and 2010: a systematic analysis for the Global Burden of Disease Study 2010 [Internet]. Vol. 380, The Lancet. 2012 [cited 2021 Apr 28]. Available from:

www.thelancet.com

3. Feigin VL, Lawes CMM, Bennett DA, Barker-Collo SL, Parag V. Review Worldwide stroke incidence and early case fatality reported in 56 population-based studies: a systematic review. 2009 [cited 202। Apr 28];355. Available from: www.thelancet.com/neurology

4. Global burden of disease injuries and risk factors study. Global Burden of Disease Profile: Zimbabwe. [Internet]. 2010 [cited 2018 Feb 14]. Available from:

http://www.healthdata.org/search?search_terms=global+burden + of + disease + profile+Zimbabwe

5. Mufunda J, Chatora R, Ndambakuwa Y, Nyarango P, Chifamba J, Kosia A, et al. Prevalence of noncommunicable diseases in Zimbabwe: Results from analysis of data from the National Central Registry and urban survey [Internet]. Vol. 16, Ethnicity and Disease. 2006 [cited 2018 Feb I4]. p. 7I8-22. Available from: 
https://ethndis.org/priorarchives/ethn-16-03-7/8.pdf

6. Gillen G. Upper trunk extremity function and management. In: Gillen G, editor. Stroke Rehabilitation A Function Based Approach. 4th ed. Elsevier Health Sciences; 2016. p. 218-79.

7. Gilmore PE, Spaulding SJ, Vandervoort AA. Hemiplegic shoulder pain: Implications for occupational therapy treatment.

8. Chae J, Mascarenhas D, Yu DT, Kirsteins A, Elovic EP, Flanagan SR, et al. Poststroke Shoulder Pain: Its Relationship to Motor Impairment, Activity Limitation, and Quality of Life. Arch Phys Med Rehabil [Internet]. 2007 Mar I [cited 2018 Mar 19];88(3):298-30 I. Available from: http://linkinghub.elsevier.com/retrieve/pii/S00039993060I5620

9. Murie-Fernández M, Carmona Iragui M, Gnanakumar V, Meyer M, Foley N, Teasell R. Painful hemiplegic shoulder in stroke patients: Causes and management. Neurol (English Ed [Internet]. 2012 May I [cited 2018 Mar 19];27(4):234-44. Available from:

https://www.sciencedirect.com/science/article/pii/ S21735808I2000478

10. Rowland T, Cooke D, Gustafsson L. Role of occupational therapy after stroke. Ann Indian Acad Neurol [Internet]. 2008 [cited 2018 Mar 19]; I I(SUPPL. 5):S99-107. Available from:

http://www.annalsofian.org/article.asp?issn $=0972-2327 ;$ year $=200$ $8 ;$ volume $=I 1$; issue $=5 ;$ spage $=99 ;$ epage $=107$; aulast $=$ Rowland

II. Townsend E, Polatajko H. Enabling occupation II [Internet]. Ottawa: Canadian Association of Occupational Therapists; 2013 [cited 2018 Mar 19]. Available from: https://scholar.googleusercontent.com/ scholar.bib?q=info:a5Lan--YATw]:scholar.google.com/\&output $=c i$ tation\&scisig=AAGBfm0AAAAAWq-QnpYZa-w_wxWVAu3587f] FHsG8W_M\&scisf $=4 \& c t=$ citation $\& \mathrm{~cd}=2 \& \mathrm{hl}=\mathrm{en}$

12. Teasell R, Foley N, Salter K, Bhogal S, Jutai J, Speechley M. EvidenceBased Review of Stroke Rehabilitation: Executive Summary, 12th Edition. Top Stroke Rehabil [Internet]. 2009 Nov 5 [cited 2018 Mar 26]; 16(6):463-88. Available from:

http://www.tandfonline.com/doi/full// 0.1310/tsr 1606-463

13. Snels IA, Beckerman H, Lankhorst GJ, Bouter LM. Treatment of hemiplegic shoulder pain in the Netherlands: results of a national survey. Clin Rehabil [Internet]. 2000 Feb [cited 2019 Nov 28]; I 4(I):20-7. Available from:

http://journals.sagepub.com/doi/10.1 I91/026921500668239/46

14. Merriam S, Tisdell E. Qualitative Research. A guide to design and implementation [Internet]. San Francisco, US: Wiley \& Sons Inc.; 2016 [cited 2021 Apr 28]. Available from: https://scholar.google. co.za/scholar?hl=en\&as_sdt $=0 \% 2 \mathrm{C} 5 \& \mathrm{q}=$ Merriam $+\mathrm{SB} \% 2 \mathrm{C}+\mathrm{Ti}$ sdell + E. + Qualitative + Research. $+A+$ guide + for + design + and + implementation. +San + Francisco\%3A+Wiley+and+Sons + Inc\% $3 \mathrm{~B}+2016 \& b \operatorname{tnG}=$

15. Krefting $L$. Rigor in qualitative research: The assessment of trustworthiness. Am J Occup Ther. 1991;45(3):214-22.

16. Hsieh H-F, Shannon SE. Three Approaches to Qualitative Content Analysis. Qual Health Res [Internet]. 2005 Nov [cited 2019 Nov 28]; I5(9): 1277-88. Available from: http://journals.sagepub.com/doi/10.1 I 77// 049732305276687

17. Radomski M, Latham C. Occupational therapy for physical dysfunction [Internet]. 2008 [cited 2018 Mar 19]. Available from:

https://books.google.co.za/books?hl=en\&lr=\&id=uZI5-5EfugoC \&oi $=$ fnd \&pg $=$ PR I I \&dq = occupational + therapy + for + physical + dysfunction\&ots $=$ CLu3BWMMgA\&sig $=I H Z D Q Z \_T s 7 \times 9 j 49 \mathrm{mjd}-$ nodb0MFpY

18. Turner-Stokes L, Jackson D. Shoulder pain after stroke: a review of the evidence base to inform the development of an integrated care pathway. Clin Rehabil [Internet]. 2002 May I [cited 2018 Mar 19]; 16(3):276-98. Available from:
http://journals.sagepub.com/doi/I0.1 191/0269215502cr49loa

19. Mattingly C. What is Clinical Reasoning? Am J Occup Ther. 1991;45(II):979-86.

20. Gustafsson L, Yates K. Are we applying interventions with research evidence when targeting secondary complications of the strokeaffected upper limb. Aust Occup Ther J [Internet]. 2009 Dec I [cited 2018 Mar 19];56(6):428-35. Available from: http://doi.wiley.com/I0.1 I I I/j. I440-1630.2008.00757.x

21. Edmans ]. Occupational Therapy and Stroke. [Internet]. Wiley; 201 I [cited 2018 Mar 19]. 270 p. Available from:

https://books.google.co.za/books?hl=en\&lr=\&id=RcFEDHIRcV $I C \& o i=$ fnd\&pg $=P A \mid$ 959\&dq $=$ occupational + therapy + and + stro ke\&ots $=$ oHRI NgUHCJ\&sig $=$ YpGOAtgmBmcXTe6qvEFkVpwE6 $\mathrm{Xg \# v}=$ onepage $\& \mathrm{q}=$ occupational therapy and stroke\&f $=$ false

22. Petkunas Byrne D, Ridgeway EM. Considering the Whole Body in Treatment of the Hemiplegic Upper Extremity. Top Stroke Rehabil [Internet]. 1998 Jan 2 [cited 2018 Feb 14];4(4): I4-34. Available from: http://www.tandfonline.com/doi/full/10.1310/K3X3-WN64E65M-LWG6

23. Harrison RA, Field TS. Post stroke pain: Identification, assessment, and therapy [Internet]. Vol. 39, Cerebrovascular Diseases. Karger Publishers; 2015 [cited 2018 Mar 19]. p. 190-201. Available from: http://www.ncbi.nlm.nih.gov/pubmed/25766121

24. Benaim C, Froger J, Cazottes C, Gueben D, Porte M, Desnuelle C, et al. Use of the Faces Pain Scale by left and right hemispheric stroke patients. Pain [Internet]. 2007 Mar [cited 20।8 Mar 19]; 128(I-2):52_ 8. Available from: http://www.ncbi.nlm.nih.gov/pubmed/I 7027 I54

25. Lindgren I, Jönsson AC, Norrving B, Lindgren A. Shoulder pain after stroke: A prospective population-based study. Stroke [Internet]. 2007 Feb I [cited 202I May 5];38(2):343-8. Available from: http:// ahajournals.org

26. Bender L, McKenna K. Hemiplegic shoulder pain: Defining the problem and its management [Internet]. Vol. 23, Disability and Rehabilitation. Taylor \& Francis; 2001 [cited 202I May 5]. p. 698-705. Available from:

https://www.tandfonline.com/doi/ abs/10.1080/096382801 10062149

27. Herr KA, Garand L. Assessment and measurement of pain in older adults [Internet]. Vol. 17, Clinics in Geriatric Medicine. Elsevier; 2001 [cited 2018 Mar 19]. p. 457-78. Available from: http://www.ncbi.nlm.nih.gov/pubmed/I I4597I 5

28. Adey-Wakeling Z, Liu E, Crotty M, Leyden J, Kleinig T, Anderson CS, et al. Hemiplegic Shoulder Pain Reduces Quality of Life after Acute Stroke: A Prospective Population-Based Study [Internet]. Vol. 95, American Journal of Physical Medicine and Rehabilitation. Lippincott Williams and Wilkins; 2016 [cited 202I May 5]. p. 758-63. Available from: https://journals.Iww.com/ajpmr/Fulltext/2016/10000/ Hemiplegic_Shoulder_Pain_Reduces_Quality_of_Life.7.aspx

29. Beck, A.T. and Steer, R.A. (1984), Internal consistencies of the original and revised beck depression inventory. J. Clin. Psychol., 40:1365I367. https://doi.org/I0.1002/1097-4679(1984 I I)40:6< I365::AID JCLP22704006I5>3.0.CO;2-D

30. Sheikh, J. I., \& Yesavage, J. A. (1986). Geriatric Depression Scale (GDS): Recent evidence and development of a shorter version. Clinical Gerontologist: The Journal of Aging and Mental Health, 5(I-2), I65-I73. https://doi.org/I0.1300/J0I8v05n0I_09

31. Zigmond AS, Snaith RP. The hospital anxiety and depression scale. Acta Psychiatr Scand. 1983 Jun;67(6):36I-70. https://doi.org/10.1 I I I/j. 1600-0447.1983.tb09716.x

32. Roley SS, DeLany JV, Barrows CJ, Brownrigg S, Honaker D, Sava DI, et al. Occupational therapy practice framework: domain \& practice, 
2nd edition. Am J Occup Ther. 2008;62(6):625-83.

33. de Klerk $\mathrm{S}$, Buchanan $\mathrm{H}$, Jerosch-Herold $\mathrm{C}$. The validity and clinical utility of the Disabilities of the Arm Shoulder and Hand questionnaire for hand injuries in developing country contexts: A systematic review. J Hand Ther [Internet]. 2018 Nov [cited 2017 Nov 14];3I(I):80-90.el. Available from:

http://linkinghub.elsevier.com/retrieve/pii/S0894 I I30 I 730 I I I 4

34. Dyer S, Mordaunt DA, Adey-Wakeling Z. Interventions for PostStroke Shoulder Pain: An Overview of Systematic Reviews. 2020 [cited 202। May 5]; Available from: http://doi.org/10.2147/IJGM.S200929

35. Barlak A, Unsal S, Kaya K, Sahin-Onat S, Ozel S. Poststroke shoulder pain in Turkish stroke patients: Relationship with clinical factors and functional outcomes [Internet]. Vol. 32, International Journal of Rehabilitation Research. 2009 [cited 2018 Mar 19]. p. 309-15. Available from: https://insights.ovid.com/crossref?an $=00004356-2009$ I 2000-00006

36. Ryerson S, Levit K. The shoulder in hemiplegia. In: Physical Therapy of the Shoulder. 2004. p. 263-88.

37. Marquez - Chin C, Bagher S, Zivanovic V, Popovic MR. Functional electrical stimulation therapy for severe hemiplegia: Randomized control trial revisited. Can J Occup Ther [Internet]. 2017 [cited 202I May 5];84(2):87-97. Available from:

https://journals.sagepub.com/doi/pdf/I0.1 I 77/00084I 74166683 70? casa_token $=$ BSU46Kxb3zUAAAAA:MKQgnbdaxSpFCMed Rl-eO2wAYaLw_18gdw3EPrSnvl7fZFcul2bujlQA0GvfPpE5gOnkgRalkme

38. McPhee SD, Bracciano AG, Rose BW, Brayman SJ. Physical agent modalities: A position paper [Internet]. Vol. 62, American Journal of Occupational Therapy. 2008 [cited 2018 Mar 26]. p. 69I-3. Available from: https://search.proquest.com/docview/231970358?pqorigsite $=$ gscholar

39. Sabari J, Lieberman D. Occupational therapy practice guidelines for adults with stroke. 2008;

40. Vuagnat $H$, Chantraine A. SHOULDER PAIN IN HEMIPLEGIA REVISITED : CONTRIBUTION OF FUNCTIONAL ELECTRICAL STIMULATION AND OTHER THERAPIES. J Rehabil Med [Internet]. 2003 [cited 2018 Mar 26];35:49-56. Available from: https://www.researchgate.net/profile/Hubert_Vuagnat/publication/10809032_Shoulder_pain_in_hemiplegia_revisited_Contribution_of_functional_electrical_stimulation_and_other_therapies/ links/0c960519c530bbfb0e000000/Shoulder-pain-in-hemiplegiarevisited-Contribution-of-functional-electrical-stimulation-andother-therapies.pdf

4I. Ak J, Ozukum I, Nilachandra L, Th K, Nandabir Y, Kunjabasi W. Prevalence of Hemiplegic Shoulder Pain in Post-stroke Patients - A Hospital Based Study Introduction : 2002 [cited 2018 Mar 26]; I5-9. Available from: https://www.ijpmr.com/ijpmr I 201/prevalencejoy.pdf

42. Pendleton HM, Schultz-Krohn W. Pedretti's occupational therapy: practice skills for physical dysfunction. Elsevier Health Sciences; 2013.

43. Nilsen D, Gillen G, Geller D, Hreha KP. Effectiveness of Interventions to Improve Occupational Performance of People With Motor Impairments After Stroke: An Evidence-Based Review. Am J Occup Ther [Internet]. 2016 [cited 202I May 5];69(I): I-9. Available from: http://dx.doi.org/10.5014/ajot.2015.011965

44. Kumar SS, Kumar KS. Compare constraint-induced movement therapy and bobath to improve hand functions in hemiplegic patients. Int J Curr Res Rev. 202 I Jan I; I3(I): I25-30.

45. de Klerk S, Badenhorst E, Buttle A, Mohammed F, Oberem J. Occupation-based hand therapy in South Africa: challenges and op- portunities. South African J Occup Ther [Internet]. 2016 [cited 2017 Nov 14];46(3): 10-5. Available from: http://ref.scielo.org/6y5cgg

46. World Health Organization. ICF checklist. Geneva World Heal Organ. 200I;

47. Mehdizadeh M, Mehraban AH, Zahediyannasab R. The effect of group-based occupational therapy on performance and satisfaction of stroke survivors: Pilot trail, neuro-occupational view. Basic Clin Neurosci [Internet]. 2017 [cited 202I May 6];8(I):69-76. Available from: /pmc/articles/PMC5396176/

Corresponding Author

*Lee-Ann Juliana Jacobs-Nzuzi Khuabi

Email: leeann@sun.ac.za 